\title{
The Film-Forming Characterization and Structural Analysis of Pectin from Sunflower Heads
}

\author{
Xiaoxia Peng, ${ }^{1,2}$ Guang Yang, ${ }^{1}$ Qi Yue, ${ }^{1}$ Xiaomeng Ren, ${ }^{1}$ Yifa Zhou, ${ }^{1}$ \\ and Mengshan Zhang ${ }^{1}{ }^{1}$ \\ ${ }^{1}$ Jilin Province Key Laboratory on Chemistry and Biology of Natural Drugs in Changbai Mountain, School of Life Sciences, \\ Northeast Normal University, Changchun 130024, China \\ ${ }^{2}$ Shanxi University of Chinese Medicine, Jinzhong 030619, China
}

Correspondence should be addressed to Mengshan Zhang; zhangms253@nenu.edu.cn

Received 7 September 2020; Revised 6 January 2021; Accepted 12 January 2021; Published 10 February 2021

Academic Editor: Zhi Li

Copyright (C) 2021 Xiaoxia Peng et al. This is an open access article distributed under the Creative Commons Attribution License, which permits unrestricted use, distribution, and reproduction in any medium, provided the original work is properly cited.

\begin{abstract}
A natural low-methoxyl pectin (termed AHP, DM $=25.9 \%$ ) was extracted from dried heads of sunflower and showed better filmforming performance blended with hydroxypropyl methylcellulose (HPMC). The solutions and films of different HPMC/AHP blends were characterized by viscosity, transparency, mechanical properties, loss on drying, water drop penetration time (WDPT), disintegration and SEM. In order to analyze the structure-property relationship of film forming, AHP was separated by ion-exchange chromatography and characterized. The results showed that the blends were immiscible, but the formation of AHP gel would give the blended film better mechanical properties. AHP was fractionated into one neutral fraction and two acidic fractions (AHPA-1 and AHPA-2). The analytical results showed that AHPA-1 and AHPA-2 were identified to be homogalacturonan- (HG-) rich pectins with low DM, and the molecular weights of them were estimated to be $106 \mathrm{kDa}$ and $226 \mathrm{kDa}$, respectively. Due to the high content of the HG domain, low DM and high molecular weights, AHP had excellent gelling properties induced by $\mathrm{Ca}^{2+}$ and was added to improve the film-forming properties of HPMC and to develop plant hollow capsules.
\end{abstract}

\section{Introduction}

The medicinal capsules provide a better solid dosage form for drugs with low compressibility, slow dissolution and bitter taste, and they require disintegration in the stomach as quickly as possible in most cases. Gelatin has been used in the production of capsules since the early 19 th century and still dominates the pharmaceutical capsule materials because it exhibits good film-forming and gas barrier properties [1]. However, the defects of gelatin capsules are gradually exposed with the development of science and technology and the progress of society. The higher price of the raw materials and well-recognized shortcomings of gelatin capsules, such as animal-derived ingredients, lower soft temperature and the instability of moisture in gelatin $[2,3]$, have led to attempts to use replacement substances, such as hydroxypro- pyl methylcellulose (HPMC) [4], carrageenan [5] and modified starches [6]. Although there are many patents and publications on the developing various substances for capsules, few non-gelatin capsule products have entered the market. The reasons for the less commercial success include the higher price due to the requirements for new processing facilities, as well as more complex processing conditions $[7,8]$. Due to the lower film-forming and curing properties, the preparation process of the starch capsule is difficult to control, and the brittleness and hygroscopicity of the product are high [9]. The capsule prepared with HPMC as a material has lower hardness, so it is hard to pull out from the mold without being destroyed [10], while the hardness of HPMC capsules could be improved by adding tamarind polysaccharides, carrageenan, aminated low-methoxyl pectin, gellan and broom alginan [11]. Due to the good gel properties 
without high sugar content, low-methoxyl pectin added to the HPMC capsule will give the capsule higher hardness and stability. And the HPMC/AHP blended capsule will be more suitable for the special requirements of patients with obesity, diabetes and hyperlipidemia.

Pectin, a kind of acidic polysaccharides, mainly exists in plant cell walls [12] and linings as supporting materials. It has been widely applied as the thicker [13], stabilizer [14], emulsifier [15], suspending agent [16] and gelling agent [17], and received special attentions from food [18], cosmetics and medicine industries [19]. The main molecular structure of pectin was composed of homogalacturonan (HG), rhamnogalacturonan I (RG-I), rhamnogalacturonan II (RG-II) and xylogalacturonan (XGA) [20]. HG is the linear polymer comprised of the 1,4-linked $\alpha$-D-galacturonic acid (GalA) backbone [21]. RG-I is made up of the repeating disaccharide [-4)- $\alpha-D$-Gal $p \mathrm{~A}-(1-2)-\alpha-L$-Rha $p-(1-]$, and its side branches composed mainly of neutral sugars, arabinan, galactan and arabinogalactan with highly variable structure and composition [22]. RG-II has a backbone of HG with complex and conservative side chains attached to the GalA residues [23]. XGA has a backbone of $\mathrm{HG}$ with xylopyranose as side chains attached to C-3 of GalA residues [24]. With different proportions of carbomethoxy [25], it could be divided into high-methoxyl pectin (HMP, DM > 50\%) and low-methoxyl pectin (LMP, DM $<50 \%$ ). Compared with $\mathrm{HMP}$, the quick gelling properties induced by $\mathrm{Ca}^{2+}$ and over a wider range of $\mathrm{pH}$ values without sugar of LMP are appropriate for low calorie or sugar-free food additives and ingredients of health-care medicines [19]. Up to now, most of the commercial pectin produced from citrus peel, apple pomace [26], sugar beet pulp [27], orange [28], lemon [29], banana [30] and peach [31] were HMP. And HMP is usually served to manufacture LMP by chemical or enzymatic treatment to hydrolysis of the methyl esters from galacturonic acid C-6 carboxyl groups. However, this kind of synthesized LMP is costly and has hazardous residuals brought in by chemical and enzymatic treatment. Mature sunflower (Helianthus annuus L.) heads contained 15-25\% (w/w) natural LMP with degree of methylesterification (DM) $\leq 26 \%$ $[32,33]$. Sunflower heads were usually discarded as wastes from the sunflower oil processing regardless of the high application value for recycling. Since Colin and Lemoine [34] reported the presence of a kind of special pectin from sunflower heads, several studies have been conducted to obtain a better understanding of its properties, and it was verified that LMP from sunflower heads had superior gelling properties induced by $\mathrm{Ca}^{2+}$ [35]. Whether LMP from sunflower heads has good film-forming properties as capsule ingredients has not been deeply investigated.

The objective of this research is to develop the HPMC/AHP blends as a hard capsule to overcome the lower hardness of the HPMC capsule. Firstly, the sunflower heads pectin (AHP) was extracted by $0.2 \%$ oxalic acid solution at $80^{\circ} \mathrm{C}$ for $1 \mathrm{~h}$ and then precipitated with ethanol. Then, the films with different ratios of HPMC/AHP were prepared. And the viscosity of different HPMC/AHP blended solutions, the mechanical properties, loss on drying, water vapor permeability and water drop penetration time of the films were studied. The morphologies and compatibility of different films were investigated by transparency rations and SEM. Finally, in order to find out the structure-property relationship of this novel pectin, AHP was separated by an ionexchange chromatography and purified by size exclusion chromatography into one neutral fraction and two homogeneous acidic fractions. The two acidic fractions were furthermore characterized by sugar composition analysis, highperformance gel permeation chromatography (HPGPC), FT-IR and NMR spectroscopy, successively. The results are anticipated to be not only stimulated the development of plant hollow capsule industries but also dealt with the recycling and reusing problems of sunflower heads.

\section{Results and Discussion}

2.1. Preparation AHP from Sunflower Heads. AHP from sunflower heads was extracted with $0.2 \%$ oxalic acid solution at $80^{\circ} \mathrm{C}$ for $1 \mathrm{~h}$ and precipitated with $60 \%$ ethanol with the yield up to $18.4 \%$. Monosaccharide composition analysis by highperformance liquid chromatography (HPLC) indicated that AHP consisted of GalA (92.3\%), Rha (3.7\%), Gal (2.1\%) and Ara (1.8\%) as shown in Table 1.

2.2. The Viscosity of HPMC/AHP Blends. The viscosity of film-forming dispersions is critical to film-forming properties. NDJ-1 type rotary viscometer was used to determine the viscosity of different HPMC/AHP blended solutions. Results showed that AHP had an important impact on viscosity of the dispersions (Table 2). The viscosity of HPMC solution was $2130 \mathrm{mPa} \bullet \mathrm{s}$, and the viscosities changed with different content AHP added. When the content of AHP was $5 \%, 10 \%, 15 \%$ and $20 \%$ (AHP/HPMC mass ratio), the viscosity was $2055 \mathrm{mPa} \bullet \mathrm{s}, 2785 \mathrm{mPa} \bullet \mathrm{s}, 2675 \mathrm{mPa} \bullet \mathrm{s}$ and $2530 \mathrm{mPa} \bullet$, respectively. Liquid viscosity between 2500 and $3000 \mathrm{mPa} \bullet$ s was suitable for the preparation of plant hollow capsules [36]. So, 10\% AHP, 15\% AHP and 20\% AHP blended solutions could be used to prepare plant hollow capsules.

\subsection{Properties of Films}

2.3.1. The Loss on Drying. The loss on drying (LOD) is a stability index of composite films. Data in Table 3 showed that the LOD of HPMC/AHP films were lower than that of conventional gelatin hard capsules (moisture content between $13 \%$ and 16\%) [37] and the HPMC film. However, the increasing of addition of AHP had little influence on the values of loss on drying of composite films. It manifested that even 5\% AHP could effectively eliminate the disadvantages of high loss on drying of other capsule ingredients.

2.3.2. Mechanical Properties. The mechanical properties of the films with different HPMC/AHP blends were studied by tensile testing. The tensile strength (TS) and percentage elongation at break (E) are used to describe the mechanical properties of the films. The results in Table 3 indicated that the tensile strength decreased slightly and then increased with the AHP content increasing. For elongation properties, the HPMC film had the highest value which was consistent with 
TABLE 1: Yields and monosaccharide compositions of AHPA-1 and AHPA-2.

\begin{tabular}{lcccccc}
\hline \multirow{2}{*}{ Fraction } & Yield (\%) & \multicolumn{5}{c}{ Monosaccharide } \\
& & GalA & Rha & Gal & Ara & \\
& & 92.3 & 3.7 & 2.1 & 1.8 & \\
\hline AHP & & 89.0 & 4.5 & 4.2 & 2.4 & 103 \\
AHPA-1 & 38.4 & & MDa) \\
AHPA-2 & 34.2 & 96.6 & 3.4 & 2.6 & 4.2 & 226 \\
\hline
\end{tabular}

TABLE 2: The viscosity and composition of various HPMC/AHP blended solutions.

\begin{tabular}{lcc}
\hline $\begin{array}{l}\text { Sample } \\
\text { name }\end{array}$ & Sample details & $\begin{array}{c}\text { Viscosity } \\
(\mathrm{mPa} \bullet \mathrm{s})\end{array}$ \\
\hline HPMC & HPMC forming film only & $2130(96.26)^{\mathrm{d}}$ \\
$5 \%$ AHP & AHP $:$ HPMC $=5: 95$ (mass ratio) & $2055(38.94)^{\mathrm{d}}$ \\
$10 \%$ AHP & AHP $:$ HPMC $=10: 90$ (mass ratio) & $2785(86.49)^{\mathrm{a}}$ \\
$15 \%$ AHP & AHP $:$ HPMC $=15: 85$ (mass ratio) & $2675(43.01)^{\mathrm{ab}}$ \\
$20 \%$ AHP & AHP $:$ HPMC $=20: 80$ (mass ratio) & $2530(103.52)^{\mathrm{ac}}$ \\
\hline
\end{tabular}

Average of 3 experimental determinations. An average with the same letter, in the same column, indicate no significant difference $(p<0.05)$.

the measurement results in the previous article $13.8 \pm 4.2 \%$ [37]. And the elongation of the blended films gradually decreased with the AHP content increasing. The tensile strength of the film added 10\% AHP was the lowest, which may be caused by two factors: HPMC/AHP blends were an immiscible system, and more importantly, the concentration of AHP was not high enough to form a stable gel structure. With pectin proportion increasing from $10 \%$ to $20 \%$, the films became tougher, because the typical "egg box" gel structures [38] formed by AHP and $\mathrm{Ca}^{2+}$ became more stable and tight. However, the formation of AHP gel would reduce the flexibility of films and increase the brittleness of films which was characterized by the increase of the tensile strength of the blended films and the gradual decrease of the elongation at break.

2.3.3. The Water Vapor Permeability (WVP). Water vapor permeability (WVP) is an important index to evaluate the capsule properties of protecting inner drugs from water. The water content is one of the key factors affecting the stability of solid pharmaceutical preparations, which could cause hydrolysis reaction, oxidation reaction and even mildew. The lower the WVP, the better water resistance capsules have. The results for WVP of different blended films are also shown in Table 3. The HPMC film had a lower WVP, and WVP decreased with the AHP content increasing up to 5\% then increased with more AHP. And the permeability coefficient of blended films was the same as that of gelatin $\left(0.24 \mathrm{~g} \bullet \mathrm{mm} \bullet \mathrm{m}^{-2} \bullet \mathrm{h}^{-1} \bullet \mathrm{kPa}^{-1}\right)$ [39], which demonstrated that the films had a compact structure and met the demand for WVP as plant capsule ingredients.

2.3.4. Water Drop Penetration Time (WDPT). WDPT is the limitation time of capsule disintegrating, which was a physical dissolving process of pharmaceutical preparations before absorption. It indirectly reflects the water solubility of HPMC/AHP blended films. The value of WDPT/d is smaller, and the permeability of the films is better. As shown in Table 3, the WDPT/d of blended films decreased with the AHP content increasing. The results showed that AHP was more hydrophilic, and the addition of AHP to HPMC would improve the water solubility and disintegration of blended films, which is significance for capsule materials.

2.3.5. Transparency. The pure HPMC solution is reasonably clear, and the transparency ratios of the blended films measured by UV spectrum are shown in Table 3 . It is seen that the transparency ratios of films decreased with the AHP content increasing. This phenomenon indicated that the HPMC/AHP blended system was immiscible since phase separation results in the low transparency [10]. And with the increase of the AHP content, the crosslinking degree between AHP and $\mathrm{Ca}^{2+}$ increased, which promoted the low-methoxyl pectin to form a typical "egg-box" gel structure. According to Yang [40], films with a higher crosslinking degree tend to exhibit decrease in transparency due to a decrease in polymer interchain spacing, allowing less light to pass through the film. Therefore, it could be speculated that the crosslinked gel structure in blended films increased with the AHP content increasing.

2.3.6. Microstructures. SEM was used to investigate the microstructures of the surfaces and the cross-sections of the blended films, as exhibited in Figure 1. The films of pure HPMC exhibited a smoother and continuous surface, and the surface roughness increased with the AHP content increasing. Some protrusions were observed on the surfaces of the films containing $15 \%$ and $20 \%$ AHP, and the density of these protrusions increased with the AHP content increasing. The results probably caused by the formation of a more rigid structure-"egg-box" gel structure-which may also be responsible for the brittle aspect of blended films. The phenomenon indicates that HPMC and AHP are two phases, but the individual surfaces generally present as a continuous phase without indication of phase separation, which means HPMC and AHP are compatible although they are immiscible [10]. The transversal sections showed that the addition of AHP affected the morphology of the blended films, since the increase of the AHP content to $10 \%$ resulted in the decrease of continuous and packed arrangement. However, the structure of film blended with $20 \%$ AHP became denser, which was the reason for its maximum tensile strength. These results were consistent with the mechanical properties of the blended films.

\subsection{Physicochemical Properties, Fractionation and Structural Analysis of AHP}

2.4.1. Fractionation of AHP. According to the method mentioned above, the DM of AHP was $25.9 \%(\mathrm{DM}<50 \%)$, indicating that AHP was a low methyl esterification pectin. Since AHP has satisfying film-forming properties, in order to clarify the structure-function relationships, the fractionation and structure analysis of AHP are necessary to be studied. Before fractionation on a semipreparative scale, AHP 
TABLE 3: Loss on drying, tensile strength (TS), elongation at break (E), water vapor permeability (WVP), water drop penetration time per film thickness (WDPT/d), and transparency of blended films.

\begin{tabular}{lcccccc}
\hline Sample name & Loss on drying (\%) & TS $(\mathrm{MPa})$ & $\mathrm{E}(\%)$ & $\mathrm{WVP}\left(\mathrm{g} \bullet \mathrm{mm} \bullet \mathrm{m}^{-2} \bullet \mathrm{h}^{-1} \bullet \mathrm{kPa}^{-1}\right)$ & WDPT/d $(\mathrm{min} / \mathrm{mm})$ & Transparency $(\%)$ \\
\hline HPMC & $8.32(0.57)^{\mathrm{a}}$ & $23.20(1.55)^{\mathrm{bc}}$ & $12.66(1.22)^{\mathrm{a}}$ & $0.165(0.01)^{\mathrm{d}}$ & $131.32(6.45)^{\mathrm{a}}$ & $87.93(0.83)^{\mathrm{a}}$ \\
$5 \%$ AHP & $6.78(0.45)^{\mathrm{bc}}$ & $21.11(1.77)^{\mathrm{bd}}$ & $5.31(0.43)^{\mathrm{bc}}$ & $0.081(0.01)^{\mathrm{e}}$ & $112.48(4.45)^{\mathrm{b}}$ & $80.61(2.14)^{\mathrm{b}}$ \\
$10 \%$ AHP & $6.63(0.37)^{\mathrm{cd}}$ & $16.87(1.26)^{\mathrm{d}}$ & $6.72(0.91)^{\mathrm{b}}$ & $0.228(0.02)^{\mathrm{ac}}$ & $100.33(5.45)^{\mathrm{bc}}$ & $73.53(2.83)^{\mathrm{c}}$ \\
$15 \%$ AHP & $6.90(0.37)^{\mathrm{b}}$ & $23.32(1.88)^{\mathrm{b}}$ & $2.93(0.29)^{\mathrm{d}}$ & $0.242(0.02)^{\mathrm{a}}$ & $93.01(3.10)^{\mathrm{cd}}$ & $64.20(4.38)^{\mathrm{cd}}$ \\
$20 \%$ AHP & $6.71(0.37)^{\mathrm{bd}}$ & $36.94(0.43)^{\mathrm{a}}$ & $1.94(0.29)^{\mathrm{e}}$ & $0.234(0.02)^{\mathrm{ab}}$ & $83.96(3.95)^{\mathrm{cd}}$ & $59.77(0.71)^{\mathrm{d}}$ \\
\hline
\end{tabular}

Average of three experimental determinations. An average with the same letter, in the same column, indicate no significant difference, $(p<0.05)$.

was analyzed on an analytical DEAE-cellulose column eluted by a linear gradient of $\mathrm{NaCl}$ (Figure 2(a)). The profile showed an unbound portion eluted with water and a bound portion eluted with linear gradient of $\mathrm{NaCl}$. The elution profile indicated that AHP contained a slight amount of neutral polysaccharides and a large proportion of acidic polysaccharides, and the peaks of two acidic polysaccharides appeared at $0.35 \mathrm{M}$ and $0.5 \mathrm{M} \mathrm{NaCl}$. So, we separated AHP on a preparative DEAE-cellulose column by elution with a stepwise gradient of $\mathrm{NaCl}$. With these steps, AHP was separated into three fractions (Figure 2(b)): AHPN eluted with water $(6.9 \%$, no further study), AHPA-1 (38.4\%) and AHPA-2 (34.2\%) eluted with $0.35 \mathrm{M}$ and $0.5 \mathrm{M} \mathrm{NaCl}$, respectively.

The molecular weight distributions of the two acidic fractions on sepharose CL-6B column were shown in Figure 3. Both AHPA-1 and AHPA-2 showed single and relatively symmetrical peaks, and the distribution of total sugars was consistent with that of uronic acid. The elution profiles from the TSK column showed single and symmetrical peaks for the two fractions (Figure 4). These results indicated that the two samples were homogeneous fractions related to molecular weights. The molecular weights were approximately deduced from the calibration curve of dextran standards by HPGPC to be $103 \mathrm{kDa}$ (AHPA-1) and $226 \mathrm{kDa}$ (AHPA-2).

The yield and monosaccharide compositions of the collected fractions from AHP are listed in Table 1. Both AHPA-1 and AHPA-2 mainly contained GalA and a small amount of Rha, Gal, and Ara. This result indicated that the two fractions were composed of pectic domains. The ratio of Rha/GalA determined for AHPA-1 was 0.051, which was among the RG-I range from 0.05 to 1.0 [41]. It suggested that AHPA-1 mainly contained $\mathrm{HG}$ domains and trace RG-I domains. AHPA-2 contained high amounts of GalA (96.6\%) and low ratio of Rha/GalA (0.035), which suggested that AHPA-2 mainly contained HG domains.

2.4.2. Structural Analysis of AHP Fractions. The FT-IR spectra of the three samples (AHP, AHPA-1 and AHPA-2) are shown in Figure 5. The major peak centered at $3400 \mathrm{~cm}^{-1}$ is due to stretching of the hydroxyl groups. The peak at $2800 \mathrm{~cm}^{-1}$ is due to the $\mathrm{C}-\mathrm{H}$ stretching of the $\mathrm{CH}_{2}$ groups, and the peak at $1412 \mathrm{~cm}^{-1}$ corresponds to vibrations of the $\mathrm{O}=\mathrm{C}-\mathrm{O}$ structure. The three samples show high wavenumber values, which constitutes the "fingerprint" region, specific for each polysaccharide. These peaks are originated from complex interacting vibrational modes and as a consequence, it is quite impossible to assign a certain peak of this region to a certain specific atom group vibration. The peak at $1740 \mathrm{~cm}^{-1}$ corresponds to the absorption of the esterified carboxylic groups of the pectin molecules, while the peak at $1610 \mathrm{~cm}^{-1}$ is attributed to the absorption of the carboxylate anions. The ratio of the area of the peak at $1740 \mathrm{~cm}^{-1}$ over the sum of the areas of the peaks at 1740 and $1610 \mathrm{~cm}^{-1}$ can be proportional to the degree of esterification of pectin. It could be seen from the ratios of the peak area that the three samples had low DM, which was consistent with the results of DM determination. And the fraction AHPA-2 had a lower DM than that of AHPA-1.

The ${ }^{13} \mathrm{C}$ NMR spectra of AHPA-1 and AHPA-2 were quite similar (Figure 6) and showed predominant resonances from carbons in free galactopyranosyl uronic acid residues in accordance with those previously observed in HG-rich pectins [42]. The signals for C- 1 to C-6 of unesterified GalA residues appeared at 97.95 (C-1), 67.09 (C-2), 67.78 (C-3), 76.87 (C-4), 70.23 (C-5) and 174.33 (C-6) ppm. C-1 to C-5 from esterified GalA residues did not give obvious signals because of the low DM, while the methyl ester carbonyl carbons and methyl group showed the diagnostic signals at 169.94 and 51.87 ppm, respectively. Combining the NMR analysis and monosaccharide composition analysis, it is deduced that AHPA-1 and AHPA-2 are HG-rich pectins with low DM, and AHPA-2 had a lower DM.

In conclusion, AHP was a natural low-methoxyl pectin extracted from sunflower heads. AHP had low DM (25.9\%), high GalA content (92.3\%), high molecular weights (103 kDa for AHPA-1 and $226 \mathrm{kDa}$ for AHPA-2), and mainly composed of HG domains, hence the conformation of AHP might be more stiff rod-like [39]. AHP had superior gelling properties and could formed the typical "egg-box" gel structure by the crosslinking with $\mathrm{Ca}^{2+}$. The properties of the HPMC/AHP blended films were related to the degree of crosslinking in the gel structure and the homogeneity of the film-forming systems. The results of the transparency test (Table 3) and SEM (Figure 1) showed that the homogeneity of blended films decreased with the increasing AHP content, which would lead to the decrease of tensile strength of the films. On the other hand, with the increase of the AHP content, the tensile strength would increase as the crosslinking in the gel structure with $\mathrm{Ca}^{2+}$. So, the tensile strength of the blended showed two-stage variation pattern (decreased slightly and then increased) with the increase of the AHP content. That of the film blended with 10\% AHP was the lowest, because the HPMC/AHP blends were immiscible, and the concentration of AHP was not high enough to form a 

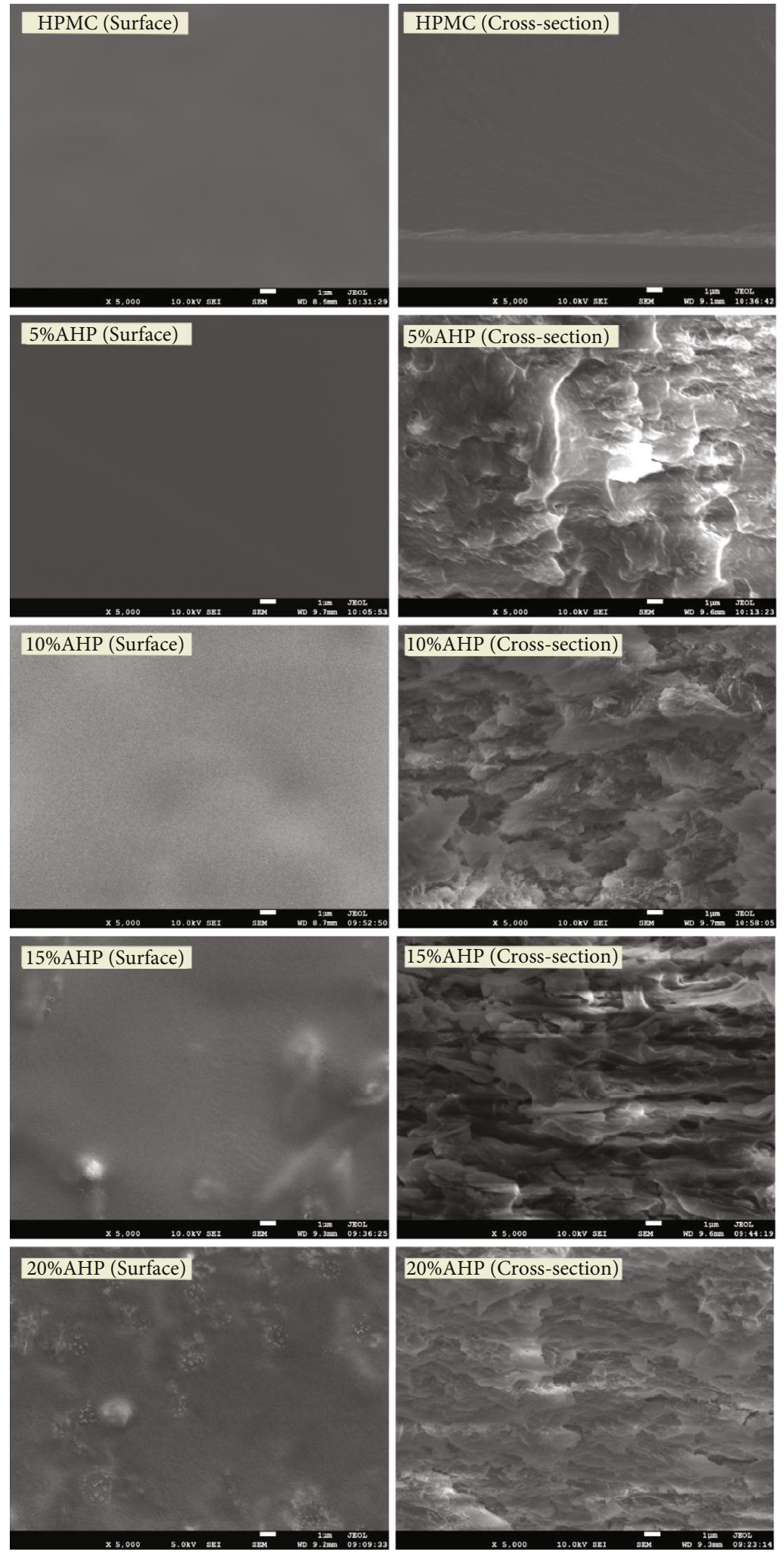

FIGURE 1: The surfaces and cross-sections of various films observed under SEM.

stable gel. And then, the addition of AHP would increase the brittleness of films and reduce the flexibility of films, which was characterized by the increase of tensile strength and the decrease of percentage elongation at break.

\section{Materials and Methods}

3.1. Materials. The dried deseeded sunflower heads used in this study were cultivated and collected from Baicheng in 


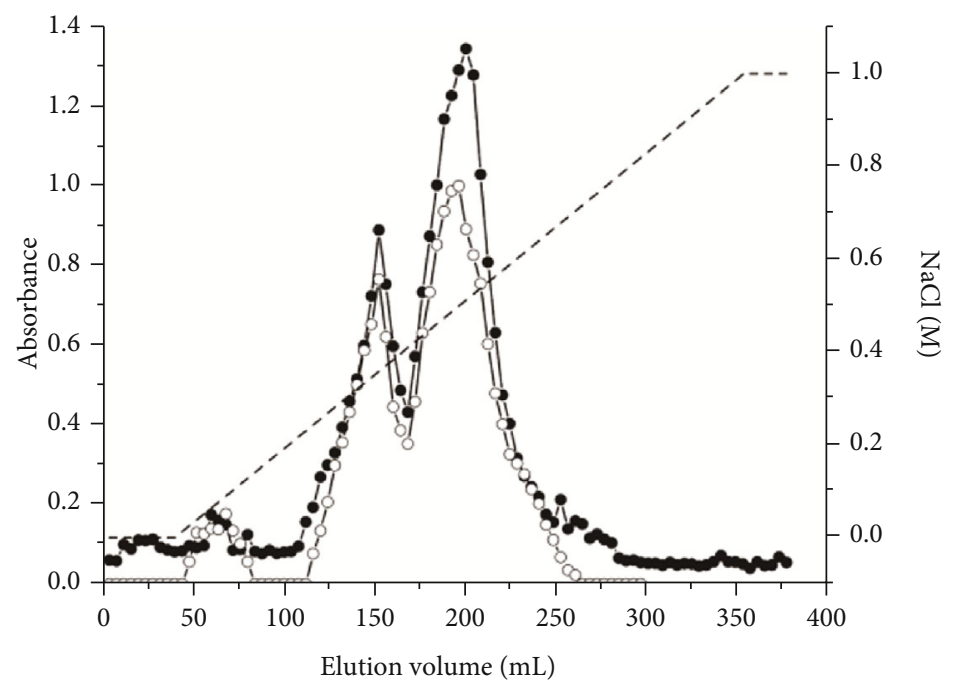

(a)

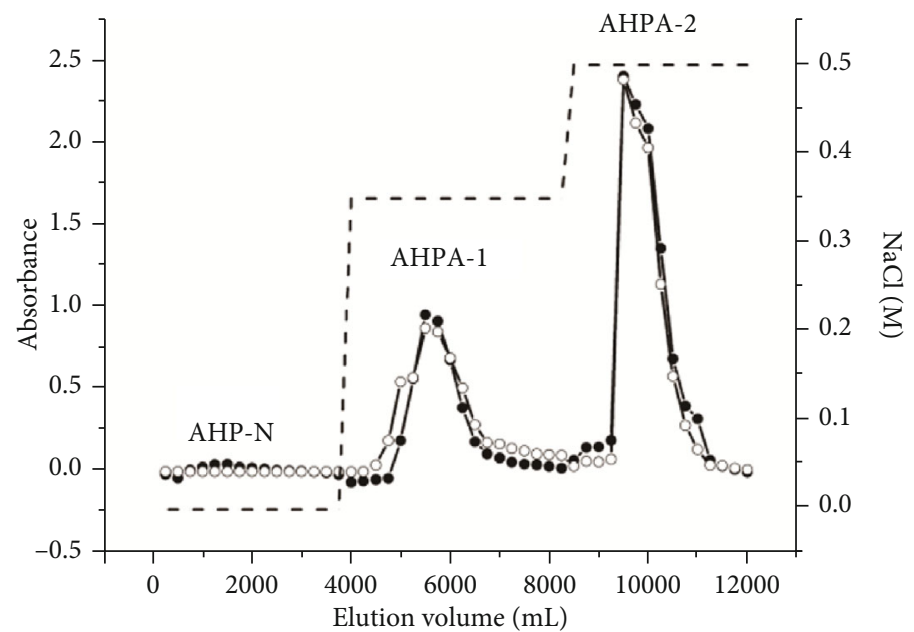

(b)

Figure 2: Elution profiles of AHP on DEAE-cellulose column, eluted by (a) a linear gradient and (b) a stepwise gradient of $\mathrm{NaCl}$, respectively (-๑-total sugars, -O-uronic acid).

Jilin province, China. A commercially available pharmaceutical grade HPMC [viscosity (2\%) 6.3 mPa॰s; pH 6.0; methoxyl content on dry basis 29\%; hydroxypropyl oxygen content on dry basis $8.4 \%$ ] was purchased from Hopetop Pharmaceutical Company, China. The DEAE-cellulose and sepharose CL-6B gel were Amersham Pharmacia Biotech products purchased from Sigma. All other reagents used were analytical grade made in China.

3.2. Isolation of Pectin from Sunflower Heads. Crushed deseeded sunflower heads (500 g) were soaked in $80 \%$ ethanol for $3 \mathrm{~h}$ to remove some colored materials, oligosaccharides, and other small molecule materials. The pretreated sunflower head was immersed $20 \mathrm{~L} 0.2 \%$ oxalic acid solution and extracted in $80^{\circ} \mathrm{C}$ for two times ( 1 hour each time). The aqueous filtrates were combined and concentrated to $2 \mathrm{~L}$. $95 \%$ ethanol was added into the filtrates until the ethanol concentration reached $60 \%$ of total volume. The precipitated pectin was collected after centrifugation and dried in a vac- uum drying oven. Then, collected pectin was dissolved in water $(10 \% \mathrm{w} / \mathrm{v})$ to remove the insoluble substances by centrifugation. The supernatant was treated with the Sevage reagent $(1: 4 \mathrm{n}$-butanol/chloroform, $\mathrm{v} / \mathrm{v})$ to remove proteins. The water phase was dialyzed against distilled water and lyophilized to obtain pectin named AHP.

\subsection{Formation of Film}

3.3.1. Solution Preparation and Viscosity Measurement. Commercial HPMC and pectin from sunflower head AHP dispersions $(100 \mathrm{~g})$ were prepared. The appropriate amount of AHP and HPMC (the sum of AHP and HPMC was kept constant at $20 \mathrm{~g}$, and the mass ratios of AHP/HPMC were fixed on $0: 100,5: 95,10: 90,15: 85$, and $20: 80$ ) and $2 \%$ plasticiser glycerol were dissolved in distilled water. The $\mathrm{pH}$ of dispersions was adjusted to 4.8 , and $1 \mathrm{~mL} \mathrm{Ca}^{2+}$ solution was added to the above dispersions in accordance with the $30 \mathrm{mg} / \mathrm{g}\left(\mathrm{Ca}^{2+} / \mathrm{AHP}\right.$ mass ratio). The suspension was heated 


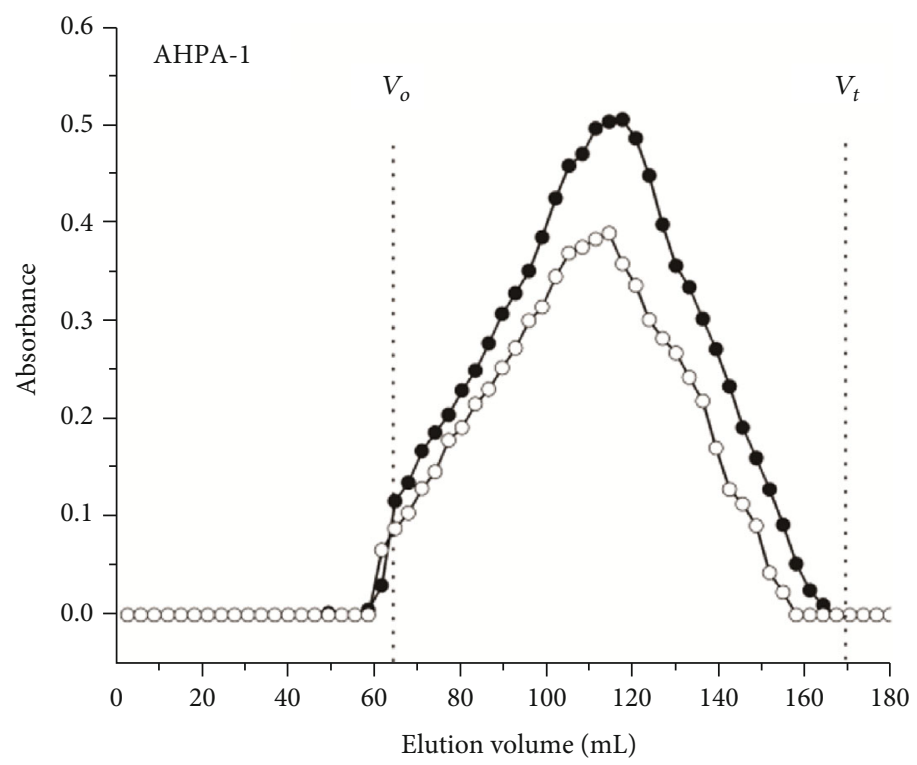

(a)

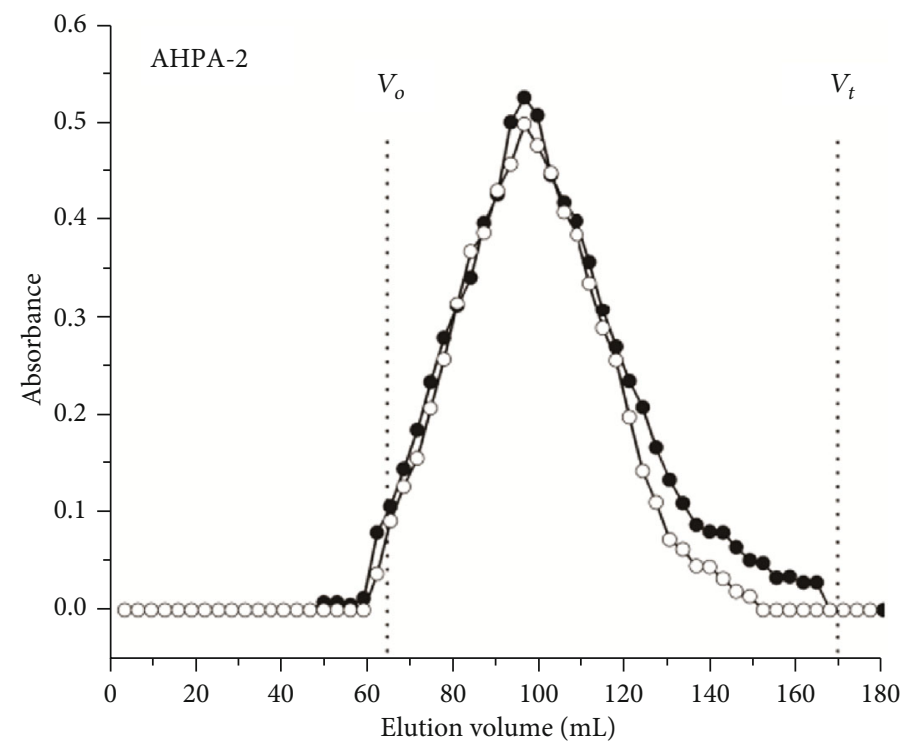

(b)

Figure 3: Elution profiles of AHPA-1 and AHPA-2 by the sepharose CL-6B column (-๑-total sugars, -O-uronic acid).

at $60^{\circ} \mathrm{C}$ with constant stirring until a homogeneous solution was obtained and then cooled down to $20^{\circ} \mathrm{C}$. The dispersions was filtered under G3 sand-core funnel and removed air bubbles from the viscous medium under vacuum. The viscosity of the biopolymer dispersions was determined by NDJ-1 type rotary viscometer at room temperature.

3.3.2. Films Preparation. The films were prepared by the traditional pouring method. Each biopolymer dispersion was poured into square glass petri dishes $(15 \mathrm{~cm} \times 15 \mathrm{~cm}=$ $225 \mathrm{~cm}^{2}$ ), and the solvent was evaporated at room temperature overnight. The films produced were removed and stored in sealed containers at room temperature and $75 \% \mathrm{RH}$ for at least one week prior to use. Vernier caliper was used to measure the thickness of the films. The average thickness of the film at 10 random positions was adopted as the mean thickness of film.

\subsection{Properties of the Films}

3.4.1. Loss on Drying. The loss on the drying test of the films was conducted as follows [43]. $0.5 \mathrm{~g}$ of the film sample was accurately weighed and placed into a constant weighing bottle and dried in a chamber at $105^{\circ} \mathrm{C}$ for $12 \mathrm{~h}$. After drying, the bottle was cooled in desiccator containing silica gel as an absorbent, and then the bottle was reweighed accurately. Loss on drying percent was calculated according to Eq. (1).

Loss on drying $(\%)=($ undried weight - dried weight $) /$ undried weight $\times 100$. 


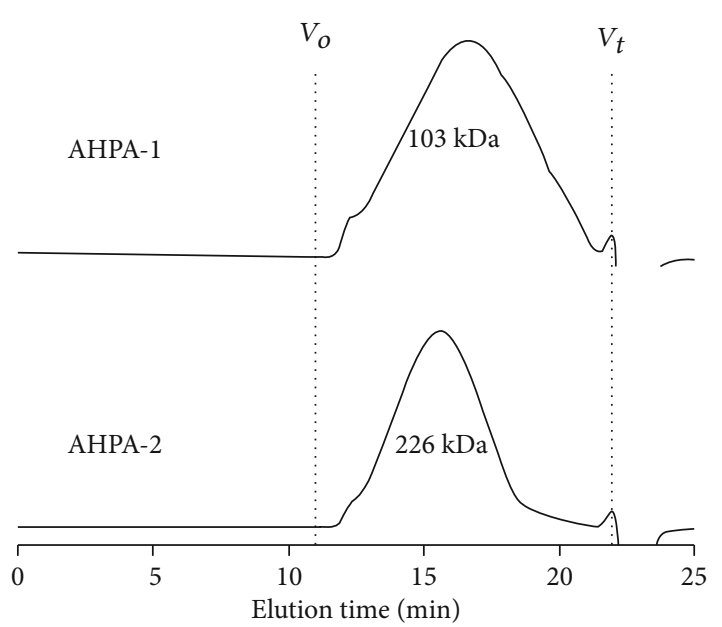

Figure 4: HPGPC elution profiles of AHPA-1 and AHPA-2.

3.4.2. Mechanical Properties. Tensile strength (TS) and percentage elongation at break (\% E) of the preconditioned films were determined at room temperature using a Texture Analyzer (TA-XT2, Stable Micro System Co. Ltd., Surrey, England) [44]. Films were cut into strips $(10.0 \mathrm{~cm} \times 2.5 \mathrm{~cm})$ and mounted between the tensile grips of the instrument. The initial grip spacing and crosshead speed were set at $5.0 \mathrm{~cm}$ and $1 \mathrm{~mm} / \mathrm{s}$, respectively. Measurements were repeated at least 3 times. A microcomputer was used to record the stress-strain curves. The tensile strength was expressed as the maximum force at break per initial crosssectional area of the film. The \% $\mathrm{E}$ was calculated by dividing the initial distance between the grips and the elongated distances until the film breaks.

3.4.3. The Water Vapor Permeability (WVP). The water vapor permeability coefficient through the films were determined gravimetrically at $25^{\circ} \mathrm{C}$ according to the ASTM method [43]. Film samples were sealed over a circular opening of a permeation cell filled with anhydrous calcium chloride maintaining a stagnant air gap of less than $1 \mathrm{~mm}$ below the film. These cells were individually kept in hermetically closed chambers $(\approx 500 \mathrm{~mL})$ containing a saturated solution of sodium chloride at $25^{\circ} \mathrm{C}$ in order to maintain a $\mathrm{RH}$ difference of $75 \%$. The salt solution in the bottom was occasionally agitated through a magnetic stirrer. After the system reached steady-state conditions $(\approx 2 \mathrm{~h})$, the cell weight was measured at every $12 \mathrm{~h}$ for 5 days. The WVP was calculated using Eq. (2). Determinations were made in triplicates.

$$
W V P=\frac{m \cdot d}{A \cdot \Delta \mathrm{RH} \cdot \mathrm{PW}},
$$

where $d$ is the film average thickness ( $\mathrm{mm}), m$ is the permeation rate $(\mathrm{g} / \mathrm{h})$ calculated by linear regression of the mass gain versus time, $A$ is the permeation area $\left(1.521 \times 10^{-3} \mathrm{~m}^{2}\right)$, $\Delta \mathrm{RH}$ is the difference in relative humidity (0.75), and $\mathrm{Pw}$ is the partial water vapor pressure at test temperature $(3.167 \mathrm{kPa})$.
3.4.4. Water Drop Penetration Time (WDPT). Relative to the disintegration time of the capsule, water drop penetration time (WDPT) was measured in the study [45]. Five drops of distilled water $\left(20^{\circ} \mathrm{C}\right)$ were applied to the film surface using a hypodermic syringe. The penetration time of the drops was recorded until the film leakage and the median penetration time were taken as representative of the WDPT of each sample. WDPT/d was described for the WDPT per film thickness, where $d$ is the thickness of composite films (mm).

3.4.5. Transparency. A UV (WFZ UV-3802) spectrum was used to measure the transparency of the different blended films, which were cut into strips $(9 \mathrm{~mm} \times 10 \mathrm{~mm})$ and placed in a $10 \mathrm{~mm} \times 10 \mathrm{~mm}$ square sample container for measurement. The transparency of films was measured at a wavelength of $206 \mathrm{~nm}$ [10]. Parallel measurements were made three times, and the mean value was calculated.

3.4.6. Microstructure. The morphologies of different films were observed under a field emission scanning electron microscope (JSM-7001F, JEOL Ltd., Japan). A $5 \mathrm{~mm} \times 5$ $\mathrm{mm}$ film was fixed on the support using silver paste and observed at a magnification of $\times 5000$. The cross-sections of the films were prepared by fracturing the films inside liquid nitrogen. All SEM samples were sputter-coated by gold particles before observation.

\subsection{Fractionation of $A H P$}

3.5.1. General Methods. The total sugar content was determined by the phenol-sulfuric acid assay using glucose as standard. Uronic acid contents were determined by the $\mathrm{m}$ hydroxydiphenyl method using galacturonic acid as a standard. Gel permeation and anion-exchange chromatographies were monitored by assaying the total sugar and uronic acid contents.

3.5.2. Analytical Chromatography on DEAE-Cellulose. AHP $(5 \mathrm{mg})$ was dissolved in distilled water $(1 \mathrm{~mL})$ and loaded on a DEAE- (diethylaminoethyl-) cellulose column $(1.5 \times$ $14 \mathrm{~cm}, \mathrm{Cl}^{-}$) pre-equilibrated with distilled water. The column was eluted first with $50 \mathrm{~mL}$ distilled water at $1.0 \mathrm{~mL} / \mathrm{min}$ and then with a linear gradient from 0 to $1.0 \mathrm{M} \mathrm{NaCl}$ within $300 \mathrm{~mL}$. The eluate was collected at $4 \mathrm{~mL}$ per tube and assayed for total sugar and uronic acid contents.

3.5.3. Semipreparative Chromatography on DEAE-Cellulose. AHP $(5 \mathrm{~g})$ was dissolved in distilled water $(100 \mathrm{~mL})$ and centrifuged. The supernatant was loaded on a DEAE-cellulose column $\left(8.0 \times 30 \mathrm{~cm}, \mathrm{Cl}^{-}\right)$and eluted by a stepwise gradient of $\mathrm{NaCl}$ aqueous solutions $(0,0.35$, and $0.5 \mathrm{M})$ at a flow rate of $13 \mathrm{~mL} / \mathrm{min}$. The eluates were collected at $200 \mathrm{~mL}$ per tube and assayed for the distribution of total sugars and uronic acids. The appropriate fractions were combined, concentrated, dialyzed against distilled water and lyophilized to give three fractions: AHPN (0.067g), AHPA-1 (1.92 g) and AHPA-2 (1.71 g).

3.5.4. Gel Permeation Chromatography on Sepharose CL-6B. Each sample $(5-10 \mathrm{mg})$ was dissolved in $0.15 \mathrm{M} \mathrm{NaCl}$ $(1 \mathrm{~mL})$, loaded onto a sepharose CL-6B column 


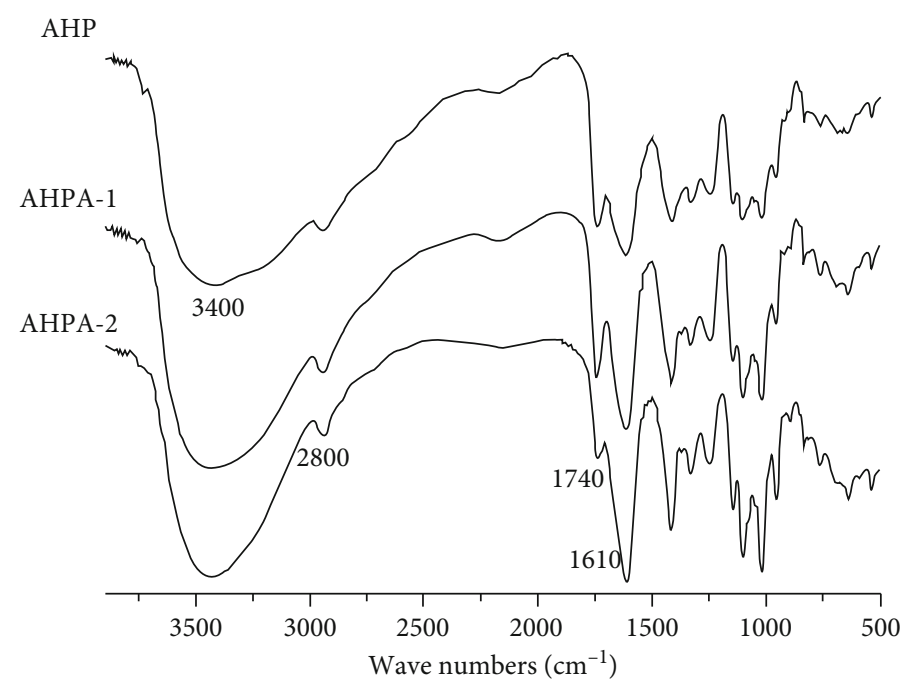

FIGURE 5: FT-IR spectra of pectins from sunflower heads.

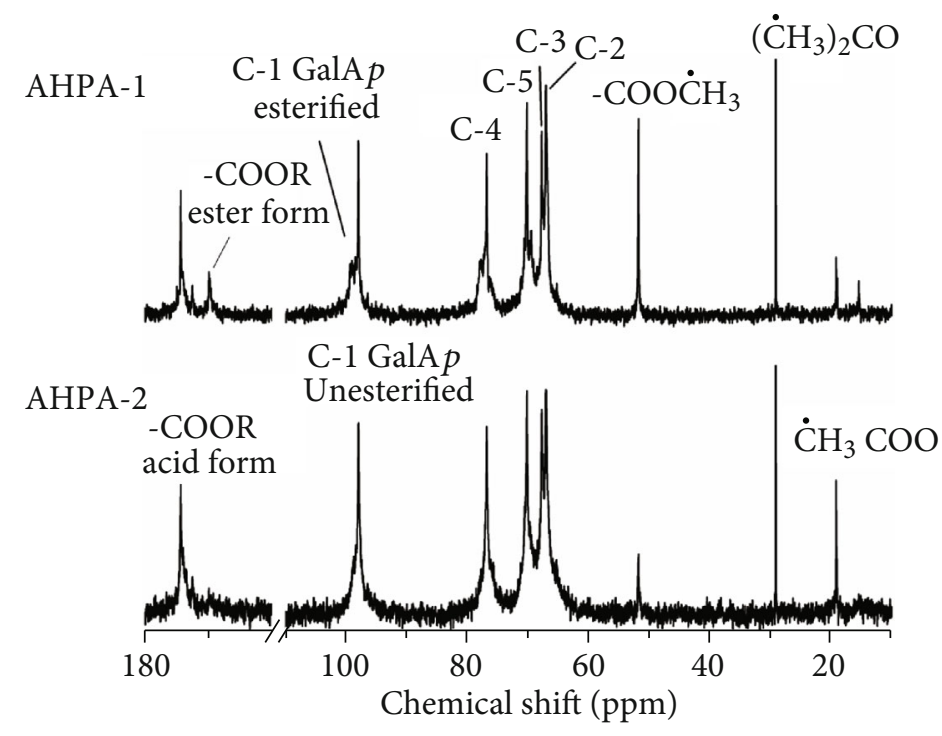

Figure $6:{ }^{13} \mathrm{C}-\mathrm{NMR}$ spectra of AHPA-1 and AHPA-2.

$(1.5 \times 90 \mathrm{~cm})$ and eluted with $0.15 \mathrm{M} \mathrm{NaCl}$ at a flow rate of $0.15 \mathrm{~mL} / \mathrm{min}$. The eluate was collected at $3 \mathrm{~mL}$ per tube and assayed for total sugar and uronic acid contents.

\subsection{Molecular Characterization of Pectin}

3.6.1. Homogeneity and Molecular Weight. Homogeneity and molecular weight were determined by HPGPC as described by Zhou [42]. It was carried out at $40^{\circ} \mathrm{C}$ using a TSK-GEL G-4000PWxl column $(7.8 \mathrm{~mm} \times 300 \mathrm{~mm}$, TOSOH, Japan $)$ connected to a Shimadzu HPLC system. The column was precalibrated with standard dextrans $(410 \mathrm{kDa}, 150 \mathrm{kDa}$, $50 \mathrm{kDa}$ and $5 \mathrm{kDa}$ ), and the elution volumes were plotted against the logarithm of their respective molecular weights. $20 \mu \mathrm{L}$ sample $(5 \mathrm{mg} / \mathrm{mL})$ was injected, eluted with $0.2 \mathrm{M}$ $\mathrm{NaCl}$ at a flow rate of $0.6 \mathrm{~mL} / \mathrm{min}$ and monitored using a refractive index RID-10A detector (Shimadzu, Tokyo,
Japan). The elution volume of pectin was plotted in the same graph, and the Mw was determined.

3.6.2. DM Determination of AHP. The degree of methyl esterification was determined by the standard titration method [46]. $0.5 \mathrm{~g}$ of pectin was dissolved in $50 \mathrm{~mL}$ distilled water and stirred for $10 \mathrm{~min}$ with $15 \mathrm{~mL}$ mixture reagent $(5 \mathrm{~mL}$ concentrated hydrochloric acid with $100 \mathrm{~mL} \mathrm{60 \%} \mathrm{ethanol).}$ The liquid was filtrated by the core funnel and washed six times with $15 \mathrm{~mL}$ mixture reagent above. Then, $60 \%$ ethanol was used to wash until no chloridion left in the liquid. The filter cake was dried for $1 \mathrm{~h}$ at $105^{\circ} \mathrm{C}$. $60-80 \mathrm{mg}$ samples were weighed and dissolved in $100 \mathrm{~mL}$ distilled water with two drops of phenolphthalein indicator. $0.02 \mathrm{~mol} / \mathrm{L} \mathrm{NaOH}$ solution was titrated until the phenolphthalein indicator become red, and the volume of $\mathrm{NaOH}$ solution was recorded $\left(V_{1}\right)$. After titration, $20 \mathrm{~mL} 0.5 \mathrm{~mol} / \mathrm{L} \mathrm{NaOH}$ solution was added 
and shaken fiercely for $15 \mathrm{~min}$. Equimolar $0.5 \mathrm{~mol} / \mathrm{L} \mathrm{HCl}$ solution was added with two drops of phenolphthalein indicator and was shaken sufficiently. $0.02 \mathrm{~mol} / \mathrm{L} \mathrm{NaOH}$ solution was used to titrate, and the volume of $\mathrm{NaOH}$ solution was recorded $\left(V_{2}\right)$. The degree of methyl esterification in pectin was obtained by calculating $V_{2} /\left(V_{1}+V_{2}\right)$.

3.6.3. Monosaccharide Composition. Monosaccharide analysis was performed by the HPLC method as described by Zhou [42]. Samples (2 mg) were hydrolyzed with anhydrous methanol containing $2 \mathrm{M} \mathrm{HCl}$ at $80^{\circ} \mathrm{C}$ for $16 \mathrm{~h}$ and then with $2 \mathrm{M}$ TFA at $120^{\circ} \mathrm{C}$ for $1 \mathrm{~h}$. The hydrolysates were derivatized with 1-phenyl-3-methyl-5-pyrazolone (PMP) and subsequently analyzed on a DIKMA Inertsil ODS-3 column $(4.6 \times 150 \mathrm{~mm})$ connected to a Shimadzu HPLC system (LC-10ATvp pump and SPD-10 AVD UV-VIS detector). The PMP derivative $(20 \mu \mathrm{L})$ was injected, eluted with $82.2 \%$ PBS (0.1 M pH 7.0) and $17.8 \%(\mathrm{v} / \mathrm{v})$ acetonitrile at a flow rate of $1.0 \mathrm{~mL} / \mathrm{min}$ and monitored by UV absorbance at $245 \mathrm{~nm}$.

3.6.4. FT-IR Analysis. Fourier transform infrared spectra were obtained on a Nicolet 6700 FT-IR spectrometer (Thermo Scientific, USA) with a DTGS detector in a range of $4000-400 \mathrm{~cm}^{-1}$. The sample was measured as a film on $\mathrm{KBr}$ discs.

3.6.5. NMR Spectroscopy. The NMR experiments were conducted as described by Yan [47]. The samples $(20 \mathrm{mg})$ were dissolved in $\mathrm{D}_{2} \mathrm{O}(99.8 \%, 0.5 \mathrm{~mL})$, freeze-dried, and redissolved in $\mathrm{D}_{2} \mathrm{O}$. The spectra were recorded at $25^{\circ} \mathrm{C}$ after 57000 scans on a Bruker Avanced $600 \mathrm{MHz}$ spectrometer (Germany), operated at $150 \mathrm{MHz}$.

3.7. Statistical Analysis. The experiment was duplicated with three observation numbers adapted for each experiment. Analysis of variance (ANOVA) was performed with raw data, and mean values and the standard errors were calculated by the Statistical Analysis System (12.5.192.7). Differences among the mean values were determined by Duncan's multiple range test, and results with $p<0.05$ were considered statistically significance.

\section{Conclusions}

In this study, the film-forming characterization and molecular structure of AHP extracted from deseeded sunflower heads have been investigated. The HPMC/AHP blended solutions showed better film-forming performance than that of pure HPMC on the aspect of viscosity, loss on drying, water vapor permeability and disintegration. AHP was also separated and purified into one neutral fraction and two acidic fractions (AHPA-1 and AHPA-2). Structure analysis showed that AHP had high content of the HG domain with low DM and high molecular weights, so AHP was speculated to have excellent gel properties. The addition of AHP could increase the brittleness of films by forming gel crosslinking structure and decrease tensile strength by making the blends more immiscible. Therefore, the natural low DM pectin from sunflower heads was satisfactory for film forming and had a good prospect as capsule ingredients in plant hollow capsule industries. It not only solved many problems having been unveiled in gelatin capsules but also improved the recycling and reusing of sunflower heads.

\section{Data Availability}

No data were used to support this study.

\section{Disclosure}

The sponsors had no role in the design, execution, interpretation, or writing of the study.

\section{Conflicts of Interest}

The authors declare no conflict of interest.

\section{Acknowledgments}

This research was funded by the National Science \& Technology Major Project "Key New Drug Creation and Manufacturing Program", China (No. 2019ZX09735001), Science \& Technology Innovation Project of Higher Education in Shanxi Province (No. 2019L0716), and the Natural Science Foundation of Jilin Province (United Fund Project) "Key Project of Free Exploration” (No. YDZJ202101ZYTS088).

\section{References}

[1] A. Duconseille, T. Astruc, N. Quintana, F. Meersman, and V. Sante-Lhoutellier, "Gelatin structure and composition linked to hard capsule dissolution: a review," Food Hydrocolloids, vol. 43, pp. 360-376, 2015.

[2] J.-H. Lee, M. R. Kim, C. H. Jo, Y. K. Jung, K. Kwon, and T. S. Kang, "Specific PCR assays to determine bovine, porcine, fish and plant origin of gelatin capsules of dietary supplements," Food Chemistry, vol. 211, pp. 253-259, 2016.

[3] A. Bigi, G. Cojazzi, S. Panzavolta, K. Rubini, and N. Roveri, "Mechanical and thermal properties of gelatin films at different degrees of glutaraldehyde crosslinking," Biomaterials, vol. 22, no. 8, pp. 763-768, 2001.

[4] H.-T. Lim, P. Balakrishnan, D. H. Oh et al., "Development of novel sibutramine base-loaded solid dispersion with gelatin and HPMC: physicochemical characterization and pharmacokinetics in beagle dogs," International Journal of Pharmaceutics, vol. 397, no. 1-2, pp. 225-230, 2010.

[5] M. C. Bonferoni, P. Chetoni, P. Giunchedi et al., "Carrageenan-gelatin mucoadhesive systems for ion-exchange based ophthalmic delivery: in vitro and preliminary in vivo studies," European Journal of Pharmaceutics and Biopharmaceutics, vol. 57, no. 3, pp. 465-472, 2004.

[6] I. Arvanitoyannis, E. Psomiadou, A. Nakayama, S. Aiba, and N. Yamamoto, "Edible films made from gelatin, soluble starch and polyols, part 3," Food Chemistry, vol. 60, no. 4, pp. 593604, 1997.

[7] N. Zhang, H. Liu, L. Yu et al., "Developing gelatin-starch blends for use as capsule materials," Carbohydrate Polymers, vol. 92, no. 1, pp. 455-461, 2013.

[8] N. Zhang, X. Liu, L. Yu, R. Shanks, E. Petinaks, and H. Liu, "Phase composition and interface of starch-gelatin blends 
studied by synchrotron FTIR micro-spectroscopy," Carbohydrate Polymers, vol. 95, no. 2, pp. 649-653, 2013.

[9] C. Yu, H. Shaokai, L. Quanliang et al., "The preparations of modified starch compounded with potatoand its applicationin empty capsule," Journal of Green ence and Technology, vol. 4, pp. 196-199, 2016.

[10] L. Zhang, Y. Wang, H. Liu et al., "Developing hydroxypropyl methylcellulose/hydroxypropyl starch blends for use as capsule materials," Carbohydrate Polymers, vol. 98, no. 1, pp. 73-79, 2013.

[11] H. N. M. Chambi and C. R. F. Grosso, "Mechanical and water vapor permeability properties of biodegradables films based on methylcellulose, glucomannan, pectin and gelatin," Ciência e Tecnologia de Alimentos, vol. 31, no. 3, pp. 739-746, 2011.

[12] M. C. Jarvis, "Structure and properties of pectin gels in plant cell walls," Plant, Cell \& Environment, vol. 7, no. 3, pp. 153164, 1984.

[13] K. Protte, J. Weiss, J. Hinrichs, and A. Knaapila, “Thermally stabilised whey protein-pectin complexes modulate the thermodynamic incompatibility in hydrocolloid matrixes: a feasibility-study on sensory and rheological characteristics in dairy desserts," LWT, vol. 105, pp. 336-343, 2019.

[14] K. Xu, M. Guo, J. du, and Z. Zhang, "Okra polysaccharide: effect on the texture and microstructure of set yoghurt as a new natural stabilizer," International Journal of Biological Macromolecules, vol. 133, pp. 117-126, 2019.

[15] H. Zhuang, S. Chu, P. Wang et al., "Study on the emulsifying properties of pomegranate peel pectin from different cultivation areas," Molecules, vol. 24, no. 9, 2019.

[16] K. Liao, P. Li, G. Chen, and X. Qiu, "Preparation and release properties of flufiprole-loaded microcapsules with core status of solid particles, solution droplets and oil suspending agent," Journal of Macromolecular Science, Part A, vol. 56, no. 3, pp. 171-178, 2019.

[17] C. Colodel, L. C. Vriesmann, and C. L. de Oliveira Petkowicz, "Rheological characterization of a pectin extracted from ponkan (Citrus reticulata blanco cv. ponkan) peel," Food Hydrocolloids, vol. 94, pp. 326-332, 2019.

[18] Z. Zhang, R. Zhang, H. Xiao et al., "Development of a standardized food model for studying the impact of food matrix effects on the gastrointestinal fate and toxicity of ingested nanomaterials," NanoImpact, vol. 13, pp. 13-25, 2019.

[19] B. Jin, X. Zhou, J. Guan, S. Yan, J. Xu, and J. Chen, "Elucidation of stabilizing pickering emulsion with jackfruit filum pectinsoy protein nanoparticles obtained by photocatalysis," Journal of Dispersion Science and Technology, vol. 40, no. 6, pp. 909917, 2019.

[20] D. A. Mohnen, R. A. Amos, A. K. Biswal et al., "A new model for the biochemistry of pectin synthesis: GAUTs synthesize diverse HG glycans in structurally and functionally distinct plant cell wall polymers," The FASEB Journal, vol. 33, Supplement 1, p. 216.2, 2019.

[21] M. L. Fishman, H. K. Chau, A. T. Hotchkiss Jr., A. White, R. A. Garcia, and P. H. Cooke, "Effect of long term cold storage and microwave extraction time on the physical and chemical properties of citrus pectin," Food Hydrocolloids, vol. 92, pp. 104116, 2019.

[22] S. F. Barbieri, S. da Costa Amaral, A. C. Ruthes et al., "Pectins from the pulp of gabiroba (Campomanesia xanthocarpa Berg): structural characterization and rheological behavior," Carbohydrate Polymers, vol. 214, pp. 250-258, 2019.
[23] C. C. Kim, G. R. Healey, W. J. Kelly et al., "Genomic insights from_Monoglobus pectinilyticus_: a pectin-degrading specialist bacterium in the human colon," The ISME Journal, vol. 13, no. 6, pp. 1437-1456, 2019.

[24] S. Kiruthika, M. Malathi, S. Selvasekarapandian, K. Tamilarasan, V. Moniha, and R. Manjuladevi, "Eco-friendly biopolymer electrolyte, pectin with magnesium nitrate salt, for application in electrochemical devices," Journal of Solid State Electrochemistry, vol. 23, no. 7, pp. 2181-2193, 2019.

[25] M. Güzel and Ö. Akpınar, "Valorisation of fruit by-products: production characterization of pectins from fruit peels," Food and Bioproducts Processing, vol. 115, pp. 126-133, 2019.

[26] B. M. Yapo, "Pectic substances: From simple pectic polysaccharides to complex pectins-A new hypothetical model," Carbohydrate Polymers, vol. 86, no. 2, pp. 373-385, 2011.

[27] S. Ma, S. J. Yu, X. L. Zheng, X. X. Wang, Q. D. Bao, and X. M. Guo, "Extraction, characterization and spontaneous emulsifying properties of pectin from sugar beet pulp," Carbohydrate Polymers, vol. 98, no. 1, pp. 750-753, 2013.

[28] J. Prakash Maran, S. Manikandan, K. Thirugnanasambandham, C. Vigna Nivetha, and R. Dinesh, "Box-Behnken design based statistical modeling for ultrasound-assisted extraction of corn silk polysaccharide," Carbohydrate Polymers, vol. 92, no. 1, pp. 604-611, 2013.

[29] M. Masmoudi, S. Besbes, M. Chaabouni et al., "Optimization of pectin extraction from lemon by-product with acidified date juice using response surface methodology," Carbohydrate Polymers, vol. 74, no. 2, pp. 185-192, 2008.

[30] T. H. Emaga, S. N. Ronkart, C. Robert, B. Wathelet, and M. Paquot, "Characterisation of pectins extracted from banana peels (Musa AAA) under different conditions using an experimental design," Food Chemistry, vol. 108, no. 2, pp. 463471, 2008.

[31] J. Pagan, A. Ibarz, and M. Llorca, "Extraction and characterization of pectin from stored peach pomace," Food Research International, vol. 34, no. 7, pp. 605-612, 2001.

[32] T. Krivorotova, A. Cirkovas, S. Maciulyte et al., "Nisin-loaded pectin nanoparticles for food preservation," Food Hydrocolloids, vol. 54, pp. 49-56, 2016.

[33] X. Peng, G. Yang, Y. Shi, Y. Zhou, M. Zhang, and S. Li, “BoxBehnken design based statistical modeling for the extraction and physicochemical properties of pectin from sunflower heads and the comparison with commercial low-methoxyl pectin," Scientific Reports, vol. 10, 2020.

[34] G. Antolína, F. V. Tinautb, Y. Briceñoc, V. Castañoc, C. Pérezb, and A. I. Ramírez, "Optimisation of biodiesel production by sunflower oil transesterification," Bioresource Technology, vol. 83, no. 2, pp. 111-114, 2002.

[35] V. Marechal and L. Rigal, "Characterization of by-products of sunflower culture - commercial applications for stalks and heads," Industrial Crops and Products, vol. 10, no. 3, pp. 185-200, 1999.

[36] M.-W. Chang, E. Stride, and M. Edirisinghe, "A new method for the preparation of monoporous hollow microspheres," Langmuir, vol. 26, no. 7, pp. 5115-5121, 2010.

[37] H. J. Bae, D. S. Cha, W. S. Whiteside, and H. J. Park, "Film and pharmaceutical hard capsule formation properties of mungbean, waterchestnut, and sweet potato starches," Food Chemistry, vol. 106, no. 1, pp. 96-105, 2008.

[38] G. T. Grant, E. R. Morris, D. A. Rees, P. J. C. Smith, and D. Thom, "Biological interactions between polysaccharides 
and divalent cations: the egg-box model," FEBS Letters, vol. 32, no. 1, pp. 195-198, 1973.

[39] S. Peng, L. H. Niu, K. Q. Lai, and Y. Q. Huang, "Physicochemical properties of biodegradable tilapia skin gelatin film and gelatin-polysaccharide based composite films," Advanced Materials Research, vol. 941-944, pp. 1133-1140, 2014.

[40] A. T. Paulson and L. Yang, "Effects of lipids on mechanical and moisture barrier properties of edible gellan film," Food Research International, vol. 33, no. 7, pp. 571-578, 2000.

[41] L. Yu, X. Zhang, S. Li et al., "Rhamnogalacturonan I domains from ginseng pectin," Carbohydrate Polymers, vol. 79, no. 4, pp. 811-817, 2010.

[42] M. Zhang, H. Zu, X. Zhuang et al., "Structural analyses of the HG-type pectin from_notopterygium incisum_and its effects on galectins," International Journal of Biological Macromolecules, vol. 162, pp. 1035-1043, 2020.

[43] A. C. K. Bierhalz, M. A. D. Silva, and T. G. Kieckbusch, "Natamycin release from alginate/pectin films for food packaging applications," Journal of Food Engineering, vol. 110, no. 1, pp. 18-25, 2012.

[44] G. Zsivanovits, A. J. MacDougall, A. C. Smith, and S. G. Ring, "Material properties of concentrated pectin networks," Carbohydrate Research, vol. 339, no. 7, pp. 1317-1322, 2004.

[45] D. A. L. Leelamanie, J. Karube, and A. Yoshida, "characterizing water repellency indices: contact angle and water drop penetration time of hydrophobized sand," Soil Science \& Plant Nutrition, vol. 54, no. 2, pp. 179-187, 2008.

[46] N. Özbay, N. Oktar, and N. A. Tapan, "Esterification of free fatty acids in waste cooking oils (WCO): role of ion- exchange resins," Fuel, vol. 87, no. 10-11, pp. 1789-1798, 2008.

[47] J. Yan, L. Zhu, Y. Qu et al., "Analyses of active antioxidant polysaccharides from four edible mushrooms," International Journal of Biological Macromolecules, vol. 123, pp. 945-956, 2019. 